\title{
Crystal Growth
}

\section{Acidic Monosaccharides become Incorporated into Calcite Single Crystals**}

\author{
Arad Lang ${ }^{+}{ }^{[a]}$ Sylwia Mijowska ${ }^{+}{ }^{[a]}$ Iryna Polishchuk, ${ }^{[a]}$ Simona Fermani, ${ }^{[b]}$ Giuseppe Falini, $^{[b]}$ \\ Alexander Katsman, ${ }^{[\mathrm{a}]}$ Frédéric Marin, ${ }^{[\mathrm{c}]}$ and Boaz Pokroy*[a]
}

\begin{abstract}
Carbohydrates, along with proteins and peptides, are known to represent a major class of biomacromolecules involved in calcium carbonate biomineralization. However, in spite of multiple physical and biochemical characterizations, the explicit role of saccharide macromolecules (long chains of carbohydrate molecules) in mineral deposition is not yet understood. In this study, we investigated the influence of two common acidic monosaccharides (MSs), the two simplest forms of acidic carbohydrates, namely glucuronic and galacturonic acids, on the formation of calcite crystals in vitro. We show here that the size, morphology, and microstructure of calcite crystals are altered when they are grown
\end{abstract}

in the presence of these MSs. More importantly, these MSs were found to become incorporated into the calcite crystalline lattice and induce anisotropic lattice distortions, a phenomenon widely studied for other biomolecules related to $\mathrm{CaCO}_{3}$ biomineralization, but never before reported in the case of single MSs. Changes in the calcite lattice induced by MSs incorporation were precisely determined by high-resolution synchrotron powder X-ray diffraction. We believe that the results of this research may deepen our understanding of the interaction of saccharide polymers with an inorganic host and shed light on the implications of carbohydrates for biomineralization processes.

\section{Introduction}

Biocalcification, when considered as a process, can be viewed as the ability of living systems to produce calcified structures. These structures are usually synthesized with tailored physical properties (morphology, size, structure, hardness, resistance to fracture, and optical properties) for one or more biological functions. ${ }^{[1-7]}$ This tailoring is possible only because of the complex interplay at the nanoscale between inorganic calcium carbonate in its early stages of formation (i.e., pre-nucleation clusters, amorphous and "liquid-like" phases, ion species, and so on) and organic macromolecules that collectively form the skeletal matrix. Such interactions are indeed a sine qua non condition for driving biominerals along nonconventional crys-

[a] A. Lang, ${ }^{+}$S. Mijowska, ${ }^{+}$I. Polishchuk, A. Katsman, B. Pokroy Department of Materials Science and Engineering, and the

Russell Berrie Nanotechnology Institute, Technion-Israel Institute of Technology, Technion City, 320003 Haifa (Israel)

E-mail:bpokroy@technion.ac.il

[b] S. Fermani, G. Falini

Faculty of Chemistry, University of Bologna

2 Via Selmi, 40126 Bologna BO (Italy)

[c] F. Marin

UMR CNRS 6282 Biogeosciences, University of Burgundy-Franche-Comté 6 Boulevard Gabriel, Dijon 21000 (France)

$\left.{ }^{+}\right]$These authors contributed equally to this work.

[**] A previous version of this manuscript has been deposited on a preprint server (https://doi.org/10.1101/2020.08.03.234310).

$\square$ Supporting information and the ORCID identification number(s) for the

iD author(s) of this article can be found under: https://doi.org/10.1002/chem.202003344. tallization pathways and for generating final products that differ significantly from their abiotically produced counterpart. $^{[8-12]}$

Because proteins provide a direct link to the genetic machinery involved in calcification, a great deal of attention has been focused on skeletal matrix proteins and their interactions with calcium and/or calcium carbonate. Dozens of papers on the biochemical properties of skeletal proteins have been published over the last two decades, ${ }^{[13-16]}$ and complete skeletal protein repertoires are nowadays known to be present in corals, ${ }^{[17]}$ brachiopods, ${ }^{[18]}$ mollusks, ${ }^{[19]}$ and sea urchins. ${ }^{[20]}$ Many of these protein mixtures have been tested in vitro for their ability to inhibit the precipitation of $\mathrm{CaCO}_{3}{ }^{[10]}$ or to modify the size and morphology of calcite crystals. ${ }^{[21]}$ More surprisingly, proteins, ${ }^{[22,23]}$ or their most elementary building blocks, amino acids, ${ }^{[24-27]}$ were found to induce anisotropic lattice distortions in their calcitic, aragonitic, or vateritic crystalline hosts. Several synthetic assays also showed that other molecules can be incorporated into calcite, such as gels, ${ }^{[28,29]}$ diblock copolymer particles, ${ }^{[30]}$ and many more.

Based on the results of numerous studies, polysaccharides (PSs) are also recognized as major components of the organic matrices associated with biomineral formation, and they play a vital role in maintaining the structural integrity of organisms. However, although quantitatively important, PSs have unfortunately been neglected in biomineralization studies. This is largely because the primary structure of PSs is not directly encoded in the genome and, furthermore, their chemistry is even more complex and subtle than that of proteins. The several existing monomers may combine in linear or branched polymers 
and, for a given polymer, the general rule is polydispersity of molecular weights, charges, and monomer compositions. The discovery of PSs in calcified tissues supplied clear evidence of two classes of PSs with strikingly different properties: chitin and charged PSs. The first, representing an insoluble polymer of $\mathrm{N}$-acetylglucosamine, was found early in history to be a constituent of some mollusk shells, ${ }^{[31]}$ a fact that was confirmed much later. ${ }^{[32-35]}$ It consists of an insoluble organic matrix that forms a scaffold for the emerging mineral. ${ }^{[3,37]}$ Specific orientations of chitin fibers can promote the templating of $\mathrm{CaCO}_{3}$ in the carapaces and shells of marine animals. ${ }^{[38,39]}$ Negatively charged PSs, often referred to as "mucopolysaccharides", consist of soluble macromolecules that were first detected by histological staining, ${ }^{[40,41]}$ and later by bulk biochemical characterization. ${ }^{[42-44]}$ Whereas chitin acts as an organic framework on which biominerals grow, mucopolysaccharides are thought to have several other functions, including interaction with growing crystals of calcium carbonate during the process of biomineralization. They have also been shown to control the formation and stabilization of the amorphous phase of $\mathrm{CaCO}_{3}{ }^{[45]}$ and to switch between $\mathrm{CaCO}_{3}$ crystalline phases. ${ }^{[46]}$ Their occurrence in mollusk shell matrices led Addadi et al. ${ }^{[47]}$ to propose a molecular model in which mucopolysaccharides, by concentrating calcium ions in the vicinity of the protein template, cooperate with acidic proteins. Later, the ability to achieve mild hydrolysis and the subsequent quantification of MSs by highperformance anion-exchange chromatography using the pulsed amperometric technique allowed bulk characterization of the monosaccharide contents of the skeletal tissues of cephalopods, ${ }^{[48]}$ bivalves, ${ }^{[49]}$ brachiopods, ${ }^{[50]}$ crustaceans, $^{[51]}$ sea urchins, $^{[52,53]}$ and corals, ${ }^{[54]}$ which in some cases showed true monosaccharidic signatures. However, accurate characterization of PSs in terms of primary structure, even with the assistance of antibodies (so-called "immunolocalization" or "immunolabeling"), ${ }^{[55-57]}$ is still in its infancy in biomineralization studies, if we consider the paucity of oligosaccharide sequences obtained so far. ${ }^{[58,59]}$

Nevertheless, many studies have been published on the effect of carbohydrates (both MSs and PSs) on the kinetics of $\mathrm{CaCO}_{3}$ formation in well-controlled environments (i.e., biomimetics). ${ }^{[60-63]}$ It has been shown that the primary structure of the saccharide molecule, along with its functional side groups, orientation of the glycosidic bond, and the degree of branching, all affect the rate of $\mathrm{CaCO}_{3}$ nucleation and growth.

The purpose of this study was to evaluate the key role played by saccharides in biocalcification processes and to show that they are effective in inducing lattice distortions in calcite crystals. To this end, we focused on two acidic MSs, glucuronic acid (GlcA) and galacturonic acid (GalA). These two chemical species are the uronic acids that are most commonly found in biological systems. They derive from their respective precursors, glucose and galactose, by oxidation of C6 to carboxylic acid, thereby creating the so-called uronic acid pathway. ${ }^{[64]}$ Under physiological $\mathrm{pH}$ conditions, with $\mathrm{p} K_{\mathrm{a}}$ values of 3.2/3.3 (GlcA) and 3.51 (GalA) ${ }_{1}^{[65]}$ they are deprotonated, which means that they carry a net negative charge and are consequently prone to interact with inorganic cations. The calcium- binding abilities of GlcA and GalA have been investigated in detail, ${ }^{[6]]}$ as have those of their homopolymers, the poly-GlcA and poly-GalA, ${ }^{[67]}$ which tend to form gels in the presence of divalent cations. Additionally, it has been shown that GlcA tends to inhibit $\mathrm{CaCO}_{3}$ nucleation by stabilizing pre-nucleation clusters and delaying the nucleation time. ${ }^{[63]} \mathrm{GlcA}$ is abundant in connective tissues, in which it is one of two hexose residues that constitute the elementary motif of the chondroitin sulfate polymer ${ }^{[68]}$ and hyaluronic acid, ${ }^{[69]}$ both found in cartilage and bone tissues. GalA is less abundant than GlcA in connective tissues, but is the main component pectins, the complex sugar family found in plant cell walls. GlcA has been detected in the skeletal matrix of several calcifying metazoans, including corals, $^{[54,70]}$ brachiopods, ${ }^{[50]}$ two crayfishes (Pacifastacus leniusculus and Orconectes limosus) ${ }^{[71]}$ the land snail Helix aspersa maxima ${ }^{[72]}$ the freshwater snail Lymnaea stagnalis, ${ }^{[73]}$ the cephalopod Nautilus macromphalus ${ }^{[74]}$ and also Nautilin-63, ${ }^{[75]}$ and the sea urchin Arbacia lixula. ${ }^{[2,53]}$ In the same samples, the occurrence of GalA is irregular, having been detected only in the shell matrix of $N$. macromphalus ${ }^{[74]}$ and not in that of Nautilin$63,{ }^{[75]}$ in one crayfish only $(O$. limosus $),{ }^{[71]}$ and in the test matrix of the sea urchin A. lixula. ${ }^{[52,53]}$

In non-metazoan biocalcifications, uronic acids have been well described as monomeric constituents of PSs of coccoliths (the calcified plates of coccolithophore algae). In particular, a PS enriched in D-galacturonic acid was identified in Emiliania huxleyi ${ }^{[76]}$ and its primary structure was solved. ${ }^{[77]}$ Further biochemical characterization showed that the galacturonic acid residues, through their carboxy groups and not their ester sulfate groups, are solely responsible for the inhibition of $\mathrm{CaCO}_{3}$ precipitation, ${ }^{[78]}$ a property that establishes uronic acids as key players in the interaction with calcium carbonate. Later, the presence of uronic acids in the PSs of coccoliths was detected in several strains and species. ${ }^{[79-81]}$ Interestingly, two recent papers attribute lattice distortions in calcite to the incorporation of coccolith macromolecules. ${ }^{[82,83]}$ However, none of the reports firmly establishes the types of molecules, purified or not, responsible for this effect. To fully understand such polysaccharide-mineral interactions, we need to start at the molecular level, as we did for proteins.

In this paper we describe the growth of calcite crystals under both ambient and hydrothermal (HT) conditions and in the presence of MSs, bearing in mind that the incorporation of simple carbohydrates into the crystal lattice of calcite has not been previously reported. There is no doubt that elucidation of this hitherto unfathomable mechanism could provide conclusive evidence and clarifications with regard to specific interactions between PSs and a crystalline host. We show here that GlcA and GalA, as monomers, can become incorporated into calcite in relatively large amounts, and accordingly, might contribute substantially to the lattice distortions in biogenic calcite.

\section{Results and Discussion}

To determine the feasibility of MSs incorporation into the calcite lattice, we used the vapor diffusion (VD) method and grew 
calcite crystals in the presence of $0.15 \mathrm{M}$ GlcA or GalA under ambient conditions (see the Experimental Section). Calcite crystals were collected after $48 \mathrm{~h}$ and characterized. High-resolution scanning electron microscopy (HRSEM) clearly revealed changes in the morphologies and shapes of the calcite crystals grown in the presence of each of the MSs compared with the traditional rhombohedral shape of the pure calcite (Figure 1). The sizes and morphologies of the crystals (see the low-magnification images in Figure S1 in the Supporting Information) are representative of the whole crystal population. The calciteGalA crystals retained the rhombohedral structure, but displayed rough and deformed facets (Figure $1 \mathrm{~b}$ ). Interestingly, the calcite-GlcA crystals exhibited an elongated scalenohedrallike morphology (Figure 1c), resembling that observed for calcite crystals containing high amounts of incorporated amino acids, in particular aspartic acid. ${ }^{[2]}$ As also seen in Figure 1, the calcite-GalA crystals reached a size of about $1 \mathrm{~mm}$, whereas the calcite-GlcA crystals were about $100 \mu \mathrm{m}$ in size. These first observations indirectly indicate that the MSs probably become incorporated into the lattice of the calcite crystals.

Our recent study of the growth of calcite crystals in the presence of amino acids and under HT conditions indicated that both high temperature and high pressure promote the incorporation of amino acids and lead to significantly higher levels of incorporation than achieved under ambient conditions. ${ }^{[26]}$ We therefore attempted to further increase the loading of MSs by using the HT method (see the Experimental Section). Calcite growth experiments were performed at $134^{\circ} \mathrm{C}$ and a water pressure of around $0.3 \mathrm{MPa}$ for $4 \mathrm{~h}$. To follow the concentration-dependent effects, we added GlcA or GalA at concentrations of $0.075,0.1$, or $0.15 \mathrm{M}$ to the reactant solution. As can be seen from Figure 2, changes in the morphology of calcite crystals grown by HT synthesis were indeed governed by the concentration of the added MSs. However, no significant change in particle size was observed (for comparison, an image of the corresponding pure calcite is presented in Figure $\mathrm{S} 1$ in the Supporting Information). Calcite crystals precipitated at lower GlcA and GalA molarities $(0.075$ and $0.1 \mathrm{M})$ maintained the rhombohedral morphology, although the crystals displayed rough facets (Figure $2 \mathrm{a}, \mathrm{b}, \mathrm{d}, \mathrm{e}$ ). At the highest concentration $(0.15 \mathrm{M})$, the crystal morphologies were akin to that of scalenohedral calcite, with elongated facets (Figure $2 c, f$ ), similar to that observed in the case of aspartic acid incorporated ${ }^{[26]}$ via the HT method.
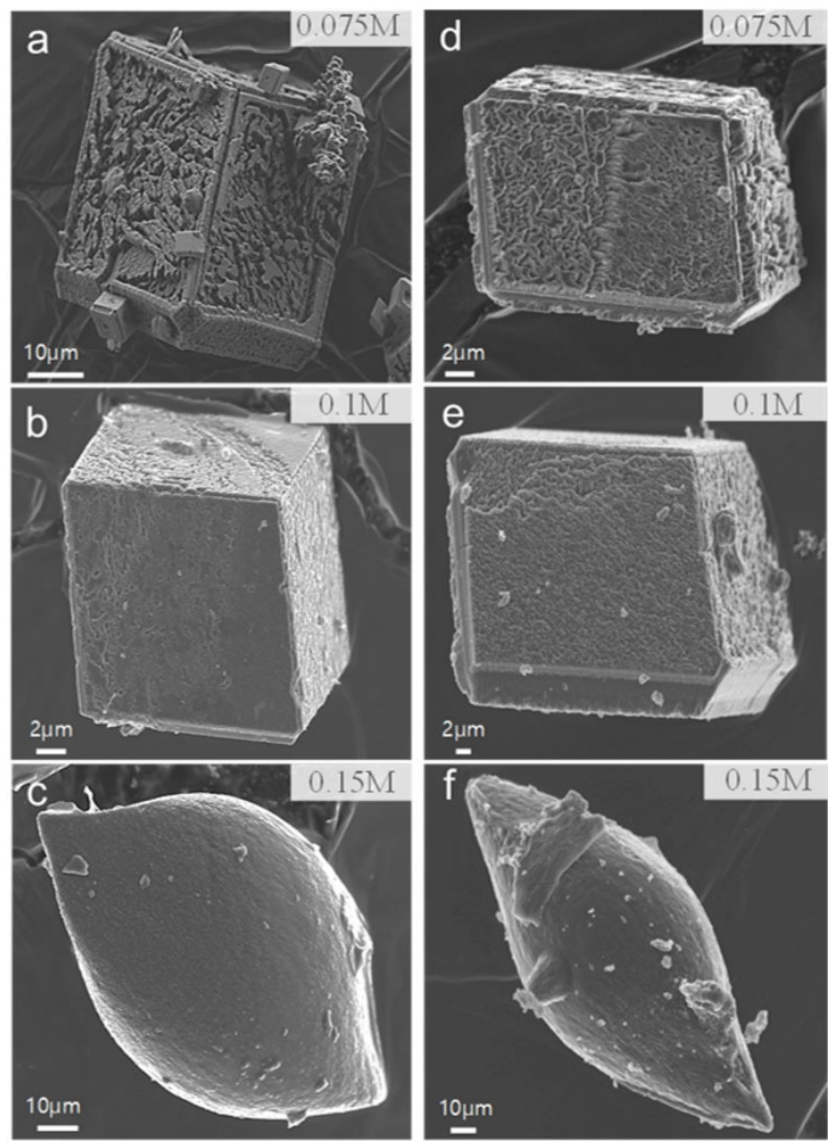

Figure 2. HRSEM images of calcite crystals synthesized by the HT method in the presence of different concentrations of MSs. Calcite in the presence of: a) 0.075 , b) 0.1 , and c) $0.15 \mathrm{M} \mathrm{GalA}$, and with d) 0.075 , e) 0.1 , and f) $0.15 \mathrm{M}$ of GIcA.

We employed synchrotron high-resolution powder X-ray diffraction (HRPXRD) to precisely determine the lattice parameters of crystals grown in the presence of GlcA or GalA by both the VD and HT methods. This technique has been shown to be the most sensitive and accurate method for determining the presence of intracrystalline molecules. ${ }^{[22-24,84]}$ Diffraction patterns were collected from as-grown samples and from samples annealed ex situ at $300^{\circ} \mathrm{C}$ for $3 \mathrm{~h}$. The initial data analysis showed that for both growing methods, the samples containing MSs were pure calcite, and that only control samples consisted of calcite together with small amounts of vaterite impurity (see Figure S2 in the Supporting Information). The 104, 006,
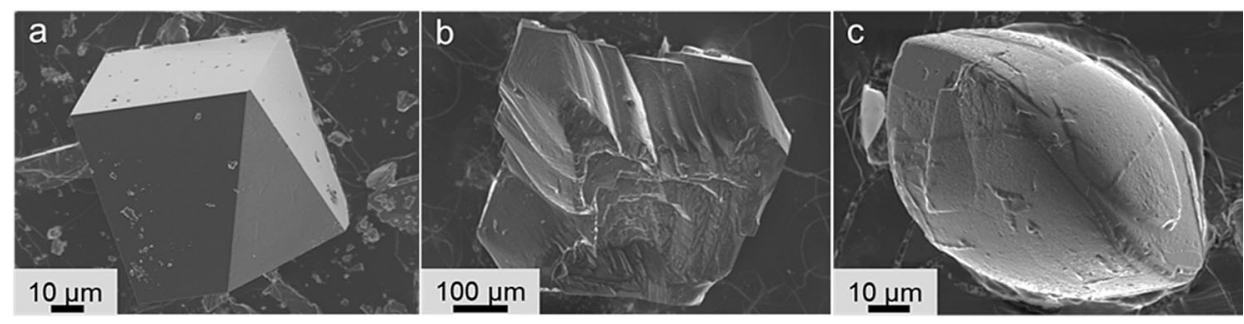

Figure 1. HRSEM images of calcite crystals prepared by the VD method. a) A pure calcite crystal and calcite crystals formed in the presence of: b) GalA and c) GICA. 
and 110 diffraction peaks were explicitly analyzed to evaluate the influence of the MSs on the $c$ and $a$ parameters of the calcite unit cell. Figure 3 shows the evolution of the 104, 006, and 110 diffraction peaks, both before and after annealing, of the calcite samples grown by HT or VD in the presence of $0.15 \mathrm{M}$ GlcA or GalA. For both growing methods, our first observation was the presence of shifts in the positions of all diffraction peaks relative to those of the calcite control (Figure 3 and Figure S4). Moreover, the higher the concentration of MS in the reactant solution, the larger the shift of the diffraction peaks (see Figure S3 for the HT method). These observations strongly support our suggestion that the MSs indeed become incorporated into the crystalline structure of calcite and induce distortions in its lattice. However, as observed by the magnitude of the diffraction peak shifts, the level of incorporation is higher in the case of the HT method than the VD method of synthesis, a phenomenon that we have already reported in the case of aspartic acid incorporation. ${ }^{[2]}$ Moreover, although the 104 and 006 diffraction peaks demonstrate a shift towards lower $2 \theta$ upon incorporation of the MSs by the VD and HT methods (Figure $3 a, b$ and Figures S3 and S4), the 110 diffraction peak shifts in the opposite direction, towards higher $2 \theta$ angles, in the case of calcite crystals grown by the HT method solely (Figure $3 c, d)$. These findings imply that whereas the calcite lattice expands in all crystallographic directions when incorporation occurs under ambient conditions (i.e., the VD method), under HT growth conditions, shrinkage occurs along the $a$ axis only. Similarly to our observation in the case of aspartic acid incorporation, this lattice distortion pattern stems from the fact that when the concentration of incorporated MSs is high, a large expansion occurs along the $c$ axis, thereby contracting the $a$ axis.

For comparison, we grew calcite in the presence of $0.15 \mathrm{M}$ glucose. This MS molecule, by contrast to GalA and GlcA MSs, does not contain any acidic carboxylic acid function. Interestingly, in this case, negligible lattice distortions were detected (see Figure S5 and Table S1 in the Supporting Information). This emphasizes the importance of the acidic group in facilitating the incorporation of the MSs into the lattice of calcite, probably by the carboxylate group substituting the carbonate group or interacting with the calcium ions.

Annealing of the samples caused significant broadening of the diffraction peaks and relaxation of the lattice distortions, as shown by the shift of the diffraction peaks towards the position of the control calcite sample (Figure 3). Even though such temperature-induced relaxation is a common feature in crystals that incorporate organic molecules, the lattice distortions caused by the incorporated MSs under HT conditions were not fully removed after annealing. This can be clearly seen for the 006 and 110 diffraction peaks before and after annealing (Fig- a
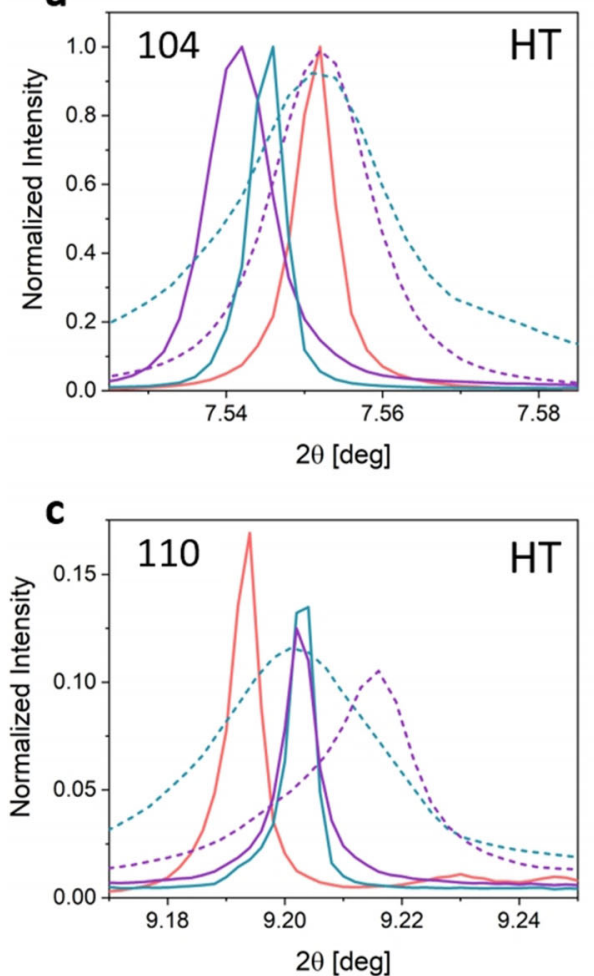

b

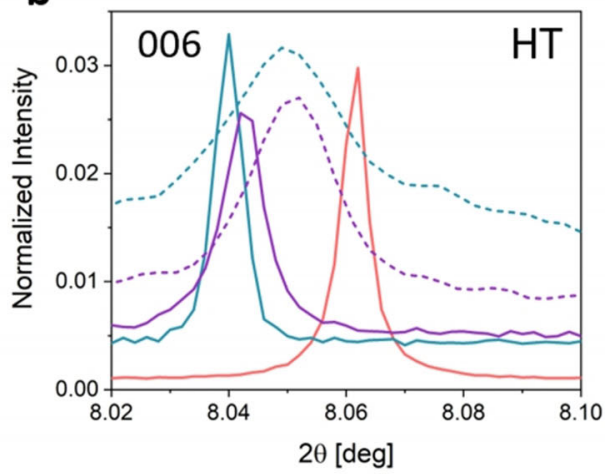

d

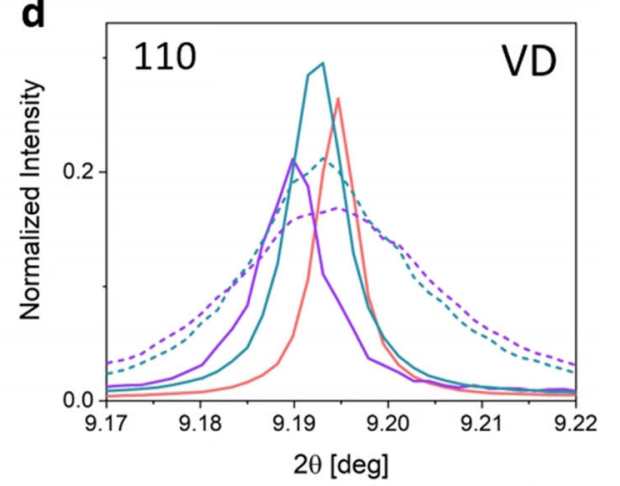

Calcite control

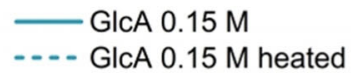

GalA $0.15 \mathrm{M}$

-.-- GIcA 0.15 M heated

Figure 3. Evolution of: a) 104, b) 006 , and c) 110 diffraction profiles of calcite crystals grown by the HT method, and d) the 110 diffraction profile of calcite crystals grown by the VD method. The GalA or GICA concentration in the reactant solution was $0.15 \mathrm{M}$ for both syntheses. The XRD data were collected from as-grown crystals (solid lines) and after their annealing (dashed lines) at $300^{\circ} \mathrm{C}$ for $3 \mathrm{~h}$ and at a wavelength of $0.3999 \AA$. 
ure $3 \mathrm{~b}, \mathrm{c})$. It is evident that the MSs are more stable to temperature than amino acids, which readily decompose into $\mathrm{CO}_{2}$ and $\mathrm{NH}_{3}$ upon heating. ${ }^{[85]}$ In the case of the MSs, the carboxylic acid probably decomposes first, similarly to amino acids, whereas the sugar molecule, being much more stable, ${ }^{[86]}$ remains intact within the calcite lattice and does not allow full lattice relaxation. Rietveld refinements performed on the collected HRPXRD data enabled us to determine the lattice parameters of all the studied crystals (see Table S1 in the Supporting Information). Lattice distortions were calculated by using the equations $(\Delta a / a)_{j}=\left(a_{m j}-a_{r j}\right) / a_{r j} \quad$ and $(\Delta c / c)_{j}=\left(c_{m j}-c_{r j}\right) / c_{r j}$, in which $m$ is the MS-incorporated calcite, $r$ is the reference (pure) calcite, and $j=0.075,0.1$, or $0.15 \mathrm{M}$ (see ref. [22]). Figure 4 presents the calculated lattice distortions induced upon the incorporation of GlcA or GalA by both synthesis methods. The magnitude of the lattice distortions along the $c$ axis increases with the concentration of MS in the solution, reaching 0.278 and $0.249 \%$ for $0.15 \mathrm{M}$ GlcA and $0.15 \mathrm{M}$ GalA, respectively. In fact, these lattice distortions along the $c$ axis are larger than those reported for biogenic calcite. ${ }^{[22]}$ The $a$ lattice parameter slightly expands with low MSs concentrations $(0.075$ and $0.1 \mathrm{M})$, but shows significant contractions of -0.104 and $-0.103 \%$, respectively, upon the addition of $0.15 \mathrm{M}$ GlcA or GalA.

The broadening of diffraction peaks after annealing is a wellestablished phenomenon in biogenic crystals as well as when organic molecules become incorporated into a crystalline host. ${ }^{[87]}$ The main reason for this is that after annealing, the organics decompose and produce new interfaces, which reduces the coherence length (crystallite size) and increases the microstrain fluctuations. To measure these microstructural changes, we performed line-profiling analysis as previously described. ${ }^{[87]}$ Analysis of the 104 diffraction peak indeed confirmed the reduction in crystallite size and increase in microstrain fluctuations resulting from the annealing of samples containing incorporated MSs (see Table S2 in the Supporting Information).

To measure the concentrations of MSs within the calcite, we performed a total organic carbon (TOC) analysis. This method enables us to detect the amount of carbon solely in organic compounds, and hence to precisely quantify the amount of MS incorporated into the calcite crystal lattice. Because of the scarcity of available calcite material with the highest MSs concentrations, we performed TOC analysis on calcite crystals grown under HT conditions in the presence of $0.075 \mathrm{M} \mathrm{GlcA}$ and $0.075 \mathrm{M}$ GalA. According to the results, the amount of incorporated GalA and GlcA was as high as $1 \mathrm{wt} \%$. Interestingly, even for the lowest MS concentration of $0.075 \mathrm{M}$, for which the crystal morphology and lattice distortions were the least affected by the MSs, we still detected a relatively high incorporation (1 wt \%) for both of the MSs used. Previous reports on biogenic and synthetic calcite crystals containing organic inclusions clearly verified the direct correlation between the magnitude of induced lattice distortion and the amount of incorporated organics. ${ }^{[24-26]}$ We may therefore conclude here that the MS concentrations within crystals displaying larger lattice distortions exceed $1 \mathrm{wt} \%$.

We also aimed to define the direction of growth of the calcite crystals containing incorporated MSs. Using high-resolution transmission electron microscopy (HRTEM), we analyzed the calcite sample grown in the presence of $0.15 \mathrm{M} \mathrm{GlcA}$ (which displayed the most prominent elongation and showed the most altered lattice parameters). Measurements were obtained from a lamella taken from the short axis of the crystal, prepared by a focused ion beam (FIB; Figure 5, inset). The bright-field image (Figure $5 \mathrm{a}$ ) reveals an undisrupted crystalline lattice. Electron diffraction analysis confirmed the singlecrystalline character of the crystal and its elongation along [211] (Figure $5 \mathrm{~b}$ ). To confirm that the crystals are indeed single crystals, we conducted single-crystal X-ray diffraction (SCXRD) measurements using a synchrotron source. Indeed, all three examined samples (calcite control, calcite-GlcA, and calcite-GalA) showed single-crystalline characteristics. The measured lattice distortions, according to the lattice parameters obtained by SCXRD, together with representative SCXRD frames, are presented in Figure $S 6$ in the Supporting Information.

To gain a better understanding of the observed anisotropic distortion, we developed a model to explain the mechanism of MSs incorporation into calcite. Here, similarly to the case of

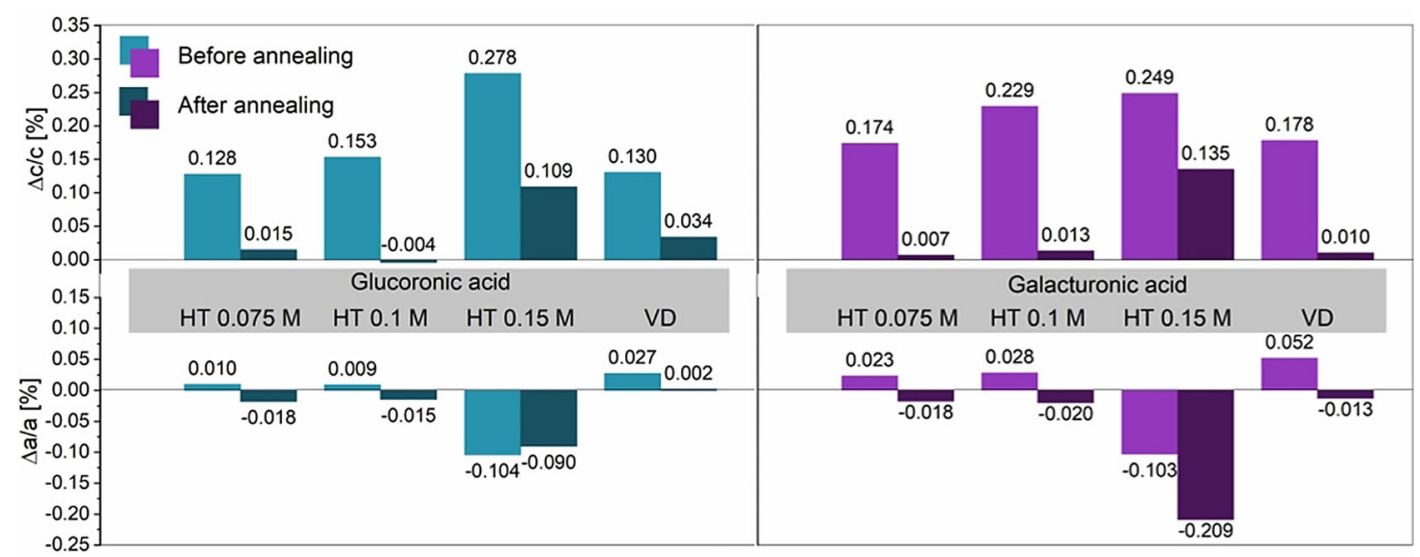

Figure 4. Lattice distortions induced in calcite samples grown by the HT or VD method and in the presence of $0.075,0.01$, or $0.15 \mathrm{M}$ of GlcA (left) or GalA (right). Top: distortions in the $c$ parameter; bottom: distortions in the $a$ parameter. 

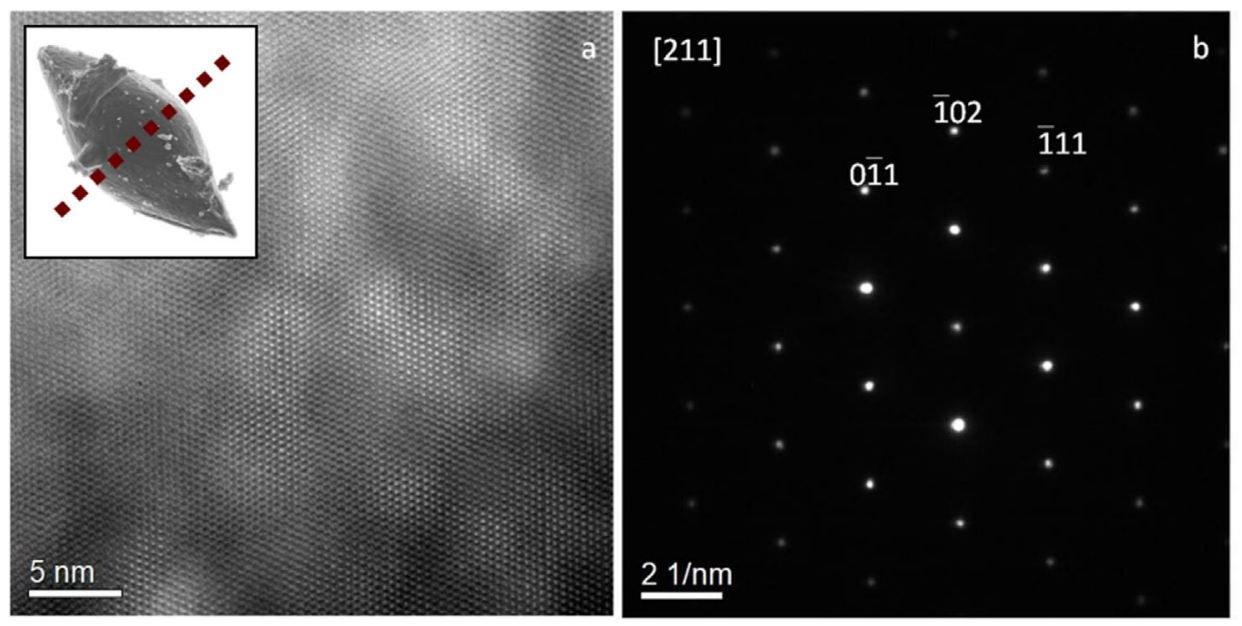

Figure 5. HRTEM analysis showing: a) the bright field image of calcite with GlcA, and b) electron diffraction pattern showing the single-crystalline character of the crystal. Inset: Illustration of the FIB-cut direction.

amino acids, ${ }^{[25]}$ we assumed that incorporation occurs by replacement of a carbonate anion of calcite with a carboxylate group of the MS molecule. The rest of the molecule occupies a possible free volume between adjacent carbonate groups. However, when the MSs is incorporated in a sufficiently high concentration, some of the MSs molecules may become incorporated as a cluster of two (or more) molecules. We considered the incorporation of dimolecules of MSs (DMSs). In this case, the two carboxylate groups of the DMSs may replace two adjacent carbonate anions, and thereby form a "molecular bridge" inside the calcite lattice. The distance between carbonate anions in the plane normal to the $c$ axis equals the calcite lattice parameter, that is, $l_{\mathrm{cc}}^{\text {in }}=a$, and the distance between carbonate anions located in adjacent carbonate planes is given by $l_{\mathrm{cc}}^{\text {out }}=\sqrt{a^{2} / 3+(c / 6)^{2}}$. If the distance between two carboxylate groups of a DMS $\left(I_{s}\right)$ is larger than the distance between carbonate anions, that is, $I_{\mathrm{s}}>I_{\mathrm{cc}}$ one can expect lattice expansion. In the opposite case, when $I_{\mathrm{s}}<I_{\mathrm{cc}}$, the molecular bridge may result in a contraction of the calcite lattice. Using the molecular dimensions reported for $\alpha$-D-galacturonic acid, ${ }^{[88]}$ we find that $I_{\mathrm{s}}=4.8 \AA$ (see the Supporting Information) lies between $l_{\mathrm{cc}}^{\text {out }}$ and $I_{\mathrm{cc}}^{\text {in }}$ that is, $I_{\mathrm{cc}}^{\text {out }}<I_{\mathrm{s}}<I_{\mathrm{cc}}^{\text {in }}$ it is around $18.5 \%$ larger than $l_{\mathrm{cc}}^{\text {out }}=4.05 \AA$, but only slightly smaller (ca. 3.7\%) than $l_{\mathrm{cc}}^{\text {in }}=a=4.989 \AA$. Therefore, one can assume that the incorporation of DMSs along the planes normal to the $c$ axis is thermodynamically more favorable, which therefore may lead to the contraction of the calcite lattice along the $a$ direction.

Overall, the measured lattice distortion includes contributions from both nonbridging MSs and bridging DMSs. The distortions along the $a$ and $c$ axes can be estimated by using the following expressions (see the Supporting Information) [Eq. (1)]:

$$
\left\{\begin{array}{l}
\left(\frac{\Delta a}{a}\right)_{\text {tot }} \approx k_{a}\left(X-X_{b}\right)-\frac{0.037}{q\left(0.83 \cdot X_{b}^{-1 / 3}-1\right)+1} \\
\left(\frac{\Delta c}{c}\right)_{\text {tot }} \approx k_{c}\left(X-X_{b}\right)+\frac{0.049}{q\left(0.83 \cdot X_{b}^{-1 / 3}-1\right)+1}
\end{array}\right.
$$

in which $X$ is the total molar fraction of incorporated MSs molecules relative to the total number of carbonate anions in calcite, $X_{\mathrm{b}}$ is the fraction of bridging DMSs, $q$ is the ratio of the elastic stiffness coefficients of calcite and MS ( $\left.q=K_{\text {calcite }} / K_{\mathrm{MS}}\right)$, $k_{a}$ and $k_{c}$ are coefficients that depend on the MSs incorporation mode. For further details, see the Supporting information. As can be seen from Equation (1), the overall lattice distortion along the $c$ axis is always positive, that is, only expansion can occur in the $c$ direction. On the other hand, the total distortion along the $a$ axis can be either positive or negative, and the latter case can even occur at relatively high concentrations of incorporated MSs. For reasonable model parameters, the observed lattice contraction along the $a$ axis is $\Delta a / a_{0} \approx-0.1 \%$, whereas the lattice expansion along the $c$ axis is $\Delta c / c_{0}$ $\approx 0.26 \%$. These characteristic distortions in the cases of $0.15 \mathrm{M}$ GlcA and $0.15 \mathrm{M}$ GalA (see Figure 4) can be achieved at incorporated MSs concentrations of $X \approx 0.9-1.3$ (see the Supporting Information).

\section{Conclusion}

To gain a better understanding of calcium carbonate biomineralization and to emphasize the key role played by saccharide moieties in this process, we have investigated the incorporation of MSs molecules into the crystalline structure of calcite. We studied the growth of calcite crystals under ambient and hydrothermal conditions. We have shown for the first time, for both the VD and HT growing methods, that incorporation of MSs into the calcite lattice indeed takes place, and that it affects both the morphology and microstructure of the crystals. Importantly, we have shown that, as in the case of amino acid incorporation, the incorporated MSs induce anisotropic lattice distortions in calcite crystals, and that the level of lattice distortion is higher for crystals grown under HT than under ambient conditions. Moreover, we detected calcite lattice contraction in the $a$ direction at relatively high concentrations of occluded MSs, a finding never previously reported. This result is explained by our molecular bridging model, which stems from (c) 2020 Wiley-VCH GmbH 
the replacement of adjacent carbonate groups in the calcite by carboxylate groups of molecular clusters of MSs. Our results suggest that saccharides may unsuspectedly intimately interact with calcium carbonate crystals at the molecular level. We cannot exclude that such interactions may also contribute to stabilizing transiently amorphous calcium carbonate phases. They may also have an important impact on the development of innovative composite materials. In the future it will be interesting to study fossil biominerals to investigate whether this interaction is stable over time, that is, whether fossil biominerals demonstrate a relaxation of their lattice parameters (due to saccharide degradation) or whether they still exhibit lattice distortions caused by preserved acidic saccharides or other organic and saccharide-containing molecules. ${ }^{[89]}$

\section{Experimental Section}

\section{Synthesis}

$\mathrm{CaCO}_{3}$ crystals were grown in the presence of three MSs: D(+)-GlcA monohydrate (reagent grade, 97\%), D-GalA (reagent grade, 98\%), and D-Glucose (reagent grade, 98\%), all purchased from Sigma-Aldrich. Deionized water was used for the preparation of all solutions.

\section{Vapor diffusion method}

GalA $(0.15 \mathrm{M})$ or D-(+)-GlcA $(0.15 \mathrm{M})$ was added to an aqueous solution of $\mathrm{CaCl}_{2}(0.15 \mathrm{M}, 100 \mathrm{~mL})$ and stirred until the MS had dissolved. The resulting solutions in glass vials were placed in a desiccator together with a $\mathrm{CO}_{2}$ source ( $4 \mathrm{~g}$ ammonium carbonate), and left for $48 \mathrm{~h}$ to allow the synthesis to proceed. Control $\mathrm{CaCO}_{3}$ crystals were prepared using the same synthesis procedure but without the MSs.

\section{Hydrothermal method}

D-Glucose $(0.15 \mathrm{M})$ or GalA or D-(+)-GlcA in various concentrations $(0.075,0.1$, and $0.15 \mathrm{M})$ was added to an aqueous solution of $\mathrm{Na}_{2} \mathrm{CO}_{3}(0.15 \mathrm{M}, 100 \mathrm{~mL}$ each $)$ and stirred until completely dissolved. Solutions of $\mathrm{CaCl}_{2}(0.15 \mathrm{M}, 100 \mathrm{~mL})$ and $\mathrm{Na}_{2} \mathrm{CO}_{3}$ containing dissolved MS were mixed rapidly and then placed into an autoclave for $4 \mathrm{~h}$ at $134^{\circ} \mathrm{C}$ and under a water pressure of around $0.3 \mathrm{MPa}$. As a control, $\mathrm{CaCO}_{3}$ was prepared according to the same synthesis procedure but without the MSs. The resulting solutions were filtered through filter paper $(2.5 \mu \mathrm{m})$ and the recovered powders were washed several times with deionized water.

\section{High-resolution powder X-ray diffraction}

HRPXRD experiments were conducted at the ID22 beam line of the European Synchrotron Research Facility (ESRF), Grenoble, France. The experiments were carried out at wavelengths of $0.39999(168)$ and 0.49602(95) $\AA$. Each sample was loaded into a borosilicate capillary, and their XRD patterns were collected before and after ex situ annealing $\left(300^{\circ} \mathrm{C}, 3 \mathrm{~h}\right.$ in air).

\section{Focused ion beam and HRTEM}

A cross-section of a calcite sample containing GlcA was prepared by using a focused gallium ion beam (Helios NanoLab G3 UC) at a voltage of $30 \mathrm{kV}$ and a current of $21 \mathrm{nA}$. Sample preparation was followed by thinning, which was achieved while maintaining a constant voltage and gradually decreasing the current from $0.43 \mathrm{nA}$ to $80 \mathrm{pA}$. The sample was polished at $5 \mathrm{kV}$ and $15 \mathrm{pA}$. The resulting FIB-cut lamella was analyzed on an FEI Titan 80-300 FEG-S/TEM in bright-field TEM mode as well as by electron diffraction.

\section{XRD data analysis}

The lattice parameters of the $\mathrm{CaCO}_{3}$ crystals were extracted by the Rietveld refinement method employing GSAS-II software. ${ }^{[90]}$ Lattice distortions were determined with high precision as in our previous studies. ${ }^{[24,26]}$ Crystallite sizes and microstrain fluctuations were determined by fitting the (104) peak, the most intense peak of calcite (see Figure S2 in the Supporting Information), to a Voigt function. ${ }^{[87]}$

\section{Total organic carbon analysis}

Calcite crystals were bleached in $25 \%(\mathrm{v} / \mathrm{v})$ sodium hypochlorite $(\mathrm{NaOCl})$ for $5 \mathrm{~min}$ to remove surface-bound organics. This treatment preserved only the intracrystalline organic molecules. The crystals were centrifuged and washed several times with deionized water. The TOC values were determined at Aminolab, Ness Ziona, Israel. In a typical measurement, a bleached sample was dissolved in $0.2 \mathrm{M} \mathrm{HCl}$, and phosphoric acid $\left(\mathrm{H}_{3} \mathrm{PO}_{4}\right)$ was then added to completely remove the total inorganic carbon. Oxidation of the organics to $\mathrm{CO}_{2}$ was initiated by adding peroxydisulfuric acid $\left(\mathrm{H}_{2} \mathrm{~S}_{2} \mathrm{O}_{8}\right)$. The amount of $\mathrm{CO}_{2}$, which is directly related to the amount of TOC in the sample, was determined by FTIR spectroscopy.

\section{Single-crystal X-ray diffraction}

The SCXRD data of single calcite crystals were collected at the ID23-1 beamline of the ESRF. The data were collected at room temperature using a wavelength of $0.85 \AA$, an oscillation angle $(\Delta \phi)$ of $1^{\circ}$ and a detector-sample distance of $129.86 \mathrm{~mm}$. The detector was a Pilatus 6M. The data was processed by using the software XDS ${ }^{[91]}$ imposing $P 1$ as space group. The unit cell axis and data collection statistics are reported in Table S3 in the Supporting Information.

\section{Acknowledgements}

This project was partially funded by the European Union Horizon 2020 Research and Innovation Program under Marie Skłodowska-Curie Grant Agreement no. 642976-NanoHeal Project. We acknowledge the European Synchrotron Radiation Facility for provision of synchrotron radiation facilities at beamline ID22.

\section{Conflict of interest}

The authors declare no conflict of interest.

Keywords: bioinspired synthesis - calcium carbonate carbohydrates $\cdot$ crystal growth $\cdot$ X-ray diffraction

[1] H. A. Lowenstam, S. Weiner, On Biomineralization, 1989.

[2] A. Heuer, D. Fink, V. Laraia, J. Arias, P. Calvert, K. Kendall, G. Messing, J. Blackwell, P. Rieke, D. Thompson, A. Et, Science 1992, 255, 1098.

[3] J. A. Raven, A. H. Knoll, Geomicrobiol. J. 2010, 27, 572.

[4] R. Blakemore, Science 1975, 190, 377. 
[5] J. C. Weaver, G. W. Milliron, A. Miserez, K. Evans-Lutterodt, S. Herrera, I. Gallana, W. J. Mershon, B. Swanson, P. Zavattieri, E. DiMasi, D. Kisailus, Science 2012, 336, 1275

[6] I. Polishchuk, A. A. Bracha, L. Bloch, D. Levy, S. Kozachkevich, Y. EtingerGeller, Y. Kauffmann, M. Burghammer, C. Giacobbe, J. Villanova, G. Hendler, C.-Y. Sun, A. J. Giuffre, M. A. Marcus, L. Kundanati, P. Zaslansky, N. M. Pugno, P. U. P. A. Gilbert, A. Katsman, B. Pokroy, Science 2017, 358, 1294.

[7] A. Hirsch, D. Gur, I. Polishchuk, D. Levy, B. Pokroy, A. J. Cruz-Cabeza, L. Addadi, L. Kronik, L. Leiserowitz, Chem. Mater. 2015, 27, 8289.

[8] J. J. De Yoreo, P. U. P. A. Gilbert, N. A. J. M. Sommerdijk, R. L. Penn, S. Whitelam, D. Joester, H. Zhang, J. D. Rimer, A. Navrotsky, J. F. Banfield A. F. Wallace, F. M. Michel, F. C. Meldrum, H. Cölfen, P. M. Dove, Science 2015, 349, aаa6760.

[9] R. T. DeVol, R. A. Metzler, L. Kabalah-Amitai, B. Pokroy, Y. Politi, A. Gal, L. Addadi, S. Weiner, A. Fernandez-Martinez, R. Demichelis, J. D. Gale, J. Ihli, F. C. Meldrum, A. Z. Blonsky, C. E. Killian, C. B. Salling, A. T. Young, M. A. Marcus, A. Scholl, A. Doran, C. Jenkins, H. A. Bechtel, P. U. P. A. Gilbert, J. Phys. Chem. B 2014, 118, 8449.

[10] A. P. Wheeler, J. W. George, C. A. Evans, Science 1981, 212, 1397

[11] D. Gebauer, H. Cölfen, Nano Today 2011, 6, 564

[12] L. B. Gower, Chem. Rev. 2008, 108, 4551.

[13] P. U. P. A. Gilbert, F. H. Wilt, Progr. Mol. Subcellular Biol. 2011, 52, 99 223.

[14] F. Marin, G. Luquet, B. Marie, D. Medakovic, Curr. Top. Devel. Biol. 2007, 80, 209-276.

[15] A. Rao, M. Drechsler, S. Schiller, M. Scheffner, D. Gebauer, H. Cölfen, Adv Funct. Mater. 2018, 28, 1802063.

[16] J. S. Evans, Proteomics 2019, 19, 1900036

[17] P. Ramos-Silva, J. Kaandorp, L. Huisman, B. Marie, I. Zanella-Cléon, N. Guichard, D. J. Miller, F. Marin, Mol. Biol. Evol. 2013, 30, 2099.

[18] D. J. Jackson, K. Mann, V. Häussermann, M. B. Schilhabel, C. Lüter, E. Griesshaber, W. Schmahl, G. Wörheide, Genome Biol. Evol. 2015, 7, 1349

[19] B. Marie, C. Joubert, A. Tayale, I. Zanella-Cleon, C. Belliard, D. Piquemal, N. Cochennec-Laureau, F. Marin, Y. Gueguen, C. Montagnani, Proc. Natl. Acad. Sci. USA 2012, 109, 20986.

[20] B. T. Livingston, C. E. Killian, F. Wilt, A. Cameron, M. J. Landrum, O. Ermolaeva, V. Sapojnikov, D. R. Maglott, A. M. Buchanan, C. A. Ettensohn, Dev. Biol. 2006, 300, 335.

[21] S. Albeck, J. Aizenberg, L. Addadi, S. Weiner, J. Am. Chem. Soc. 1993 115, 11691.

[22] B. Pokroy, A. N. Fitch, F. Marin, M. Kapon, N. Adir, E. Zolotoyabko, J. Struct. Biol. 2006, 155, 96.

[23] E. Weber, L. Bloch, C. Guth, A. N. Fitch, I. M. Weiss, B. Pokroy, Chem. Mater. 2014, 26, 4925.

[24] S. Borukhin, L. Bloch, T. Radlauer, A. H. Hill, A. N. Fitch, B. Pokroy, Adv Funct. Mater. 2012, 22, 4216.

[25] Y.-Y. Kim, J. D. Carloni, B. Demarchi, D. Sparks, D. G. Reid, M. E. Kunitake, C. C. Tang, M. J. Duer, C. L. Freeman, B. Pokroy, K. Penkman, J. H. Harding, L. A. Estroff, S. P. Baker, F. C. Meldrum, Nat. Mater. 2016, 15, 903

[26] S. Mijowska, I. Polishchuk, A. Lang, E. Seknazi, C. Dejoie, S. Fermani, G. Falini, N. Demitri, M. Polentarutti, A. Katsman, B. Pokroy, Chem. Mater 2020, 32, 4205.

[27] E. Seknazi, S. Mijowska, I. Polishchuk, B. Pokroy, Inorg. Chem. Front. 2019, 6, 2696

[28] H. Li, L. A. Estroff, Adv. Mater. 2009, 21, 470.

[29] H. Li, H. L. Xin, D. A. Muller, L. A. Estroff, Science 2009, 326, 1244

[30] C. T. Hendley, L. A. Fielding, E. R. Jones, A. J. Ryan, S. P. Armes, L. A. Estroff, J. Am. Chem. Soc. 2018, 140, 7936.

[31] W. T. Meyer, Tintenfische mit besonderer Berücksichtigung von Sepia und Octopus; Verlag von Werner Klinkhardt, Leipzig, 1913.

[32] C. Jeuniaux, Chitine et Chitinolyse: Un Chapitre de la Biologie Moléculaire, Impr. G. Thone, 1963.

[33] C. Jeuniaux, Distribution and Quantitative Importance of Chitin in Animals, Vol. 20, Station Biologique Place Georges Teissier, 29680 Roscoff, France, 1978.

[34] N. Okafor, Biochim. Biophys. Acta Mucoproteins Mucopolysaccharides $1965,101,193$

[35] P. C. H. Grégoire, Biol. Rev. 1967, 42, 653.

[36] K. M. Rudall, In Advances in Insect Physiology, Vol. 1, Academic Press, 1963, pp. $257-313$.
[37] I. M. Weiss, V. Schönitzer, J. Struct. Biol. 2006, 153, 264.

[38] A. Al-Sawalmih, C. Li, S. Siegel, H. Fabritius, S. Yi, D. Raabe, P. Fratzl, O. Paris, Adv. Funct. Mater. 2008, 18, 3307.

[39] M. Omori, N. Watabe, The Mechanisms of Biomineralization in Animals and Plants: Proceedings, Tokai University Press, Tokyo, Japan, 1980.

[40] T. Tsujii, Bull. Biogeogr. Soc. Japan 1955, 16, 88.

[41] G. Bevelander, P. Benzer, Biol. Bull. 1948, 94, 176

[42] G. Meenakshi, M. Subramaniam, Proc. Indian Acad. Sci. 1963, 57, 73.

[43] K. Simkiss, Comp. Biochem. Physiol. 1965, 16, 427.

[44] V. R. Meenakshi, B. T. Scheer, Comp. Biochem. Physiol. 1970, 34, 953.

[45] C. Zhong, C. C. Chu, Langmuir 2009, 25, 3045.

[46] M. Ø. Olderøy, M. Xie, B. L. Strand, K. I. Draget, P. Sikorski, J.-P. Andreassen, Cryst. Growth Des. 2011, 11, 520.

[47] L. Addadi, J. Moradian, E. Shay, N. G. Maroudas, S. Weiner, Proc. Natl. Acad. Sci. USA 1987, 84, 2732.

[48] Y. Dauphin, F. Marin, Experientia 1995, 51, 278.

[49] F. Immel, C. Broussard, B. Catherinet, L. Plasseraud, G. Alcaraz, I. Bundeleva, F. Marin, PLoS One 2016, 11, e0154264.

[50] D. Gaspard, F. Marin, N. Guichard, S. Morel, G. Alcaraz, G. Luquet, Earth Environ. Sci. Trans. R. Soc. Edinburgh 2007, 98, 415.

[51] G. Luquet, Zookeys 2012, 176, 103.

[52] J. M. Kanold, F. Immel, C. Broussard, N. Guichard, L. Plasseraud, M. Corneillat, G. Alcaraz, F. Brümmer, F. Marin, Comp. Biochem. Physiol. Part D 2015, 13, 24.

[53] J. M. Kanold, N. Guichard, F. Immel, L. Plasseraud, M. Corneillat, G. Alcaraz, F. Brümmer, F. Marin, FEBS J. 2015, 282, 1891.

[54] P. Ramos-Silva, J. Kaandorp, F. Herbst, L. Plasseraud, G. Alcaraz, C. Stern M. Corneillat, N. Guichard, C. Durlet, G. Luquet, F. Marin, PLoS One 2014, 9, e97454.

[55] M. E. Marsh, Protoplasma 1994, 177, 108.

[56] S. Puverel, E. Tambutte, D. Zoccola, I. Domart-Coulon, A. Bouchot, S. Lotto, D. Allemand, S. Tambutte, Coral Reefs 2005, 24, 149.

[57] M. Okazaki, S. Sakuda, N. Ozaki, T. Kogure, H. Nagasawa, Thalass. An Int. J. Mar. Sci. 2004, 20, 59.

[58] J. C. Marxen, M. Nimtz, W. Becker, K. Mann, Biochim. Biophys. Acta Proteins Proteomics 2003, 1650, 92.

[59] H. Zhou, A. J. Hanneman, N. D. Chasteen, V. N. Reinhold, J. Proteome Res. 2013, 12, 4547.

[60] A. J. Giuffre, L. M. Hamm, N. Han, J. J. De Yoreo, P. M. Dove, Proc. Natl. Acad. Sci. USA 2013, 110, 9261.

[61] J. W. Nielsen, K. K. Sand, C. S. Pedersen, L. Z. Lakshtanov, J. R. Winther, M. Willemoës, S. L. S. Stipp, Cryst. Growth Des. 2012, 12, 4906.

[62] M. Yang, S. L. S. Stipp, J. Harding, Cryst. Growth Des. 2008, 8, 4066.

[63] A. Rao, J. K. Berg, M. Kellermeier, D. Gebauer, Eur. J. Mineral. 2014, 26, 537.

[64] F. Eisenberg, Jr., P. G. Dayton, J. J. Burns, J. Biol. Chem. 1959, 234, 250

[65] R. Kohn, P. Kovác, Chem. Zvesti 1978, 32, 478.

[66] L. DeLucas, C. E. Bugg, A. Terzis, R. Rivest, Carbohydr. Res. 1975, 41, 19.

[67] I. Braccini, R. P. Grasso, S. Pérez, Carbohydr. Res. 1999, 317, 119.

[68] S. Inoue, M. Miyawaki, Anal. Biochem. 1975, 65, 164.

[69] A. Fallacara, E. Baldini, S. Manfredini, S. Vertuani, Polymers (Basel) 2018, 10, 701.

[70] A. Naggi, G. Torri, M. lacomini, G. Colombo Castelli, M. Reggi, S. Fermani, Z. Dubinsky, S. Goffredo, G. Falini, ACS Omega 2018, 3, 2895.

[71] G. Luquet, M. Fernández, A. Badou, N. Guichard, N. Roy, M. Corneillat, G. Alcaraz, J. Arias, Biomolecules 2012, 3, 18.

[72] C. Pavat, I. Zanella-Cléon, M. Becchi, D. Medakovic, G. Luquet, N. Guichard, G. Alcaraz, J.-L. Dommergues, A. Serpentini, J.-M. Lebel, F. Marin, Comp. Biochem. Physiol. Part B 2012, 161, 303.

[73] I. Herlitze, B. Marie, F. Marin, D. J. Jackson, Gigascience 2018, 7, giy056.

[74] B. Marie, F. Marin, A. Marie, L. Bédouet, L. Dubost, G. Alcaraz, C. Milet, G. Luquet, ChemBioChem 2009, 10, 1495.

[75] B. Marie, I. Zanella-Cléon, M. Corneillat, M. Becchi, G. Alcaraz, L. Plasseraud, G. Luquet, F. Marin, FEBS J. 2011, 278, 2117.

[76] A. M. J. Fichtinger-Schepman, J. P. Kamerling, J. F. G. Vliegenthart, E. W. De Jong, L. Bosch, P. Westbroek, Carbohydr. Res. 1979, 69, 181.

[77] A. M. J. Fichtinger-Schepman, J. P. Kamerling, C. Versluis, J. F. Vliegenthart, Carbohydr. Res. 1980, 86, 215.

[78] A. H. Borman, E. W. Jong, M. Huizinga, D. J. Kok, P. Westbroek, L. Bosch, Eur. J. Biochem. 1982, 129, 179.

[79] M. E. Marsh, D. P. Dickinson, Protoplasma 1997, 199, 9. 
[80] R. B. Y. Lee, D. A. I. Mavridou, G. Papadakos, H. L. O. McClelland, R. E. M. Rickaby, Nat. Commun. 2016, 7, 13144.

[81] C. E. Walker, S. Heath, D. L. Salmon, N. Smirnoff, G. Langer, A. R. Taylor, C. Brownlee, G. L. Wheeler, Front. Mar. Sci. 2018, 5, https://doi.org/ 10.3389/fmars.2018.00306.

[82] S. Frølich, H. O. Sørensen, S. S. Hakim, F. Marin, S. L. S. Stipp, H. Birkedal, Cryst. Growth Des. 2015, 15, 2761.

[83] M. A. Hood, H. Leemreize, A. Scheffel, D. Faivre, J. Struct. Biol. 2016, 196, 147.

[84] B. Pokroy, J.P. Quintana, E. N. Caspi, A. Berner, E. Zolotoyabko, Nat. Mater. 2004, 3, 900.

[85] I. M. Weiss, C. Muth, R. Drumm, H. O. K. Kirchner, BMC Biophys. 2018, 11, 2.

[86] W. Haynes, CRC Handb. Chem. Phys. 2012, 13, 5.4
[87] B. Pokroy, A. N. Fitch, E. Zolotoyabko, Adv. Mater. 2006, 18, 2363.

[88] H.-R. Tang, P. S. Belton, S. C. Davies, D. L. Hughes, Carbohydr. Res. 2001, 330, 391.

[89] M. J. Collins, C. M. Nielsen-Marsh, J. Hiller, C. I. Smith, J. P. Roberts, R. V. Prigodich, T. J. Wess, J. Csapo, A. R. Millard, G. Turner-Walker, Archaeometry 2002, 44, 383.

[90] B. H. Toby, R. B. Von Dreele, J. Appl. Crystallogr. 2013, 46, 544.

[91] W. Kabsch, Acta Crystallogr. Sect. D 2010, 66, 125.

Manuscript received: July 15, 2020

Revised manuscript received: August 13, 2020

Accepted manuscript online: August 17, 2020

Version of record online: $\square \mathbf{\square}, 0000$ 


\section{FULL PAPER}

\section{Crystal Growth}

A. Lang, S. Mijowska, I. Polishchuk, S. Fermani, G. Falini, A. Katsman,

F. Marin, B. Pokroy*

Acidic Monosaccharides become Incorporated into Calcite Single Crystals

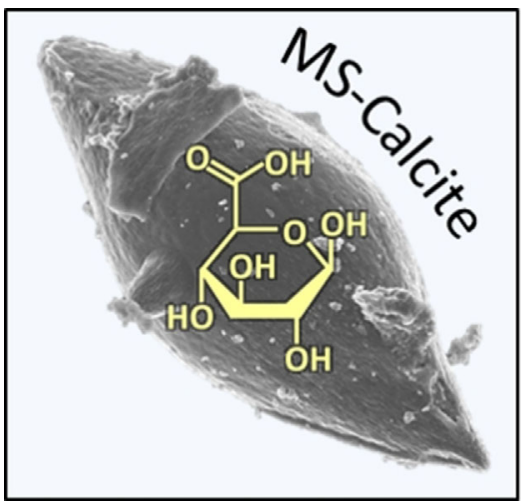

$\mathrm{CaCO}_{3}$ biomineralization: The ability to incorporate acidic monosaccharaides into calcite single crystals has been demonstrated for the first time. Such incorporation induces lattice distortions in the calcite host, along with noticeable changes in the morphology of the calcite crystal. The extent of incorporation strongly depends on the concentration of the intracrystalline monosaccharides. 